Article

\title{
The Polyphonic Sounds of Europe: Users' Engagement With Parties' European-Focused Facebook Posts
}

\author{
Márton Bene ${ }^{1,2, *}$, Melanie Magin ${ }^{3}$, Daniel Jackson ${ }^{4}$, Darren Lilleker ${ }^{4}$, Delia Balaban ${ }^{5}$, Paweł Baranowski ${ }^{6}$, \\ Jörg Haßler ${ }^{7}$, Simon Kruschinski ${ }^{8}$, and Uta Russmann ${ }^{9}$ \\ ${ }^{1}$ Centre for Social Sciences, Hungary \\ 2 Eötvös Loránd University, Hungary \\ ${ }^{3}$ Norwegian University of Science and Technology, Norway \\ ${ }^{4}$ Bournemouth University, UK \\ ${ }^{5}$ Babeș-Bolyai University, Romania \\ ${ }^{6}$ University of Wrocław, Poland \\ 7 LMU Munich, Germany \\ 8 Johannes Gutenberg University of Mainz, Germany \\ ${ }^{9}$ University of Innsbruck, Austria \\ * Corresponding author (bene.marton@tk.hu)
}

Submitted: 15 July 2021 | Accepted: 11 October 2021 | Published: 17 February 2022

\begin{abstract}
It is an old concern in public and academic debates that people are not interested in European-level issues, and even European Parliamentary election campaigns, which are the main democratic tools of the European Union (EU) to involve ordinary people into political decision-making, are mostly about national-level political topics. Moreover, even when European issues emerge, the context of its discussion is often harmful to European integration and strengthens the perceived importance of domestic politics. In the age of social media, however, users' content preferences may significantly affect the presence of different political levels in political campaigns, but these preferences are still largely uncovered in academic literature. To fill this gap, we investigate the direct and moderated effects of European-focused Facebook posts on user engagement drawing upon a content analysis dataset including 9,688 posts of 68 parties from 12 EU countries. In line with the well-known second-order election hypothesis (Reif \& Schmitt, 1980) we hypothesize a negative direct main effect. However, we also assume that this effect is moderated by several content-, and party-level factors, and when people engage with European-level contents they do it with those ones that are posted by populist parties, focused on a few divisive hot topics, and are framed with a negative tone. Moreover, we expect cross-country differences. We find that on the whole, user engagement with national-level political content prevails over the European-level, but in some countries there are no remarkable differences in user engagement patterns of the two levels. While our findings mostly confirm the second-order election hypothesis, they also demonstrate that European politics can spread within social media platforms in a less divisive and negative way than we expected. European-focused posts do not perform better when they are posted by populist parties, focused selectively on the salient issues of immigration or environment, or framed in a negative way.
\end{abstract}

\section{Keywords}

campaign; comparative research; destructive visibility; European politics; Facebook; political communication; second-order election; social media; user engagement

\section{Issue}

This article is part of the issue "Analyzing Citizen Engagement With European Politics Through Social Media" edited by Pieter de Wilde (Norwegian University of Science and Technology), Astrid Rasch (Norwegian University of Science and Technology), and Michael Bossetta (Lund University).

(C) 2022 by the author(s); licensee Cogitatio (Lisbon, Portugal). This article is licensed under a Creative Commons Attribution 4.0 International License (CC BY). 


\section{Introduction}

It is a long-standing concern that the European-level is of secondary importance behind the national-level in European politics, even in the case of European Parliament (EP) elections (Reif \& Schmitt, 1980). Scholars argue that this fact contributes to the democratic deficit of the European Union (EU; Follesdal \& Hix, 2006) and is therefore a barrier to the development and deepening of the European integration process. This second-order character of European politics can be partly explained by communication-related factors. Both mass media (de Vreese et al., 2006) and political actors (parties and politicians; Haßler et al., 2020) focus primarily on the national level, and even EU-related issues and elections are "domestified" (Boomgaarden et al., 2013) and framed in an "ethnocentric" way (Trimithiotis, 2020). Moreover, the communication context of EU-level issues that emerge in the public sphere is often harmful to the European project and even increase the perceived importance of domestic political level as they are raised by populist parties (Van Kessel, 2015), framed in a negative way (Seddone et al., 2019), and discussed only in relation to some specific divisive topics (Senninger \& Wagner, 2015). In the last few years, however, the political communication environment has significantly transformed, and it is not only media and political actors anymore who are able to shape the visibility of political topics, but citizens' social media activity can also exert remarkable influence on the public agenda (Blumler, 2016).

For these reasons, citizen engagement with political content online can shape the nature of public discourse during an election campaign, including the visibility of different political levels. However, the dynamics of these user preferences are still relatively uncovered in academic literature. We do not know, for example, to what extent people engage with European-level messages on social media platforms such as Facebook in the context of EP election campaigns, and how this is moderated by other content- and context-level factors such as associated topics, sentiment, party types, and country context.

To address these shortcomings, we test the secondorder election and the related destructive visibility theses by investigating the direct and moderated effects of European-focused Facebook posts on user engagement that were published in the last 28 days of the 2019 EP election campaign. Alongside user-engagement data, we draw upon a hand-coded content analysis dataset including 9,688 posts of 68 parties from 12 EU countries. We find that, on the whole, user engagement with national-level political content prevails over the European-level, but users do not engage with EU-level posts more when they are presented in a context that can be harmful to the EU-project: There is no engagement gap between supportive and more skeptical countries, populist parties are not more effective with their EU-focused posts, and the negatively framed and divi- sive issue-focused EU-level content is not more popular either. Such findings raise the possibility that EU-level political posts can spread in the social media public in a less divisive way than previous research might suggest.

\section{Theoretical Background}

\subsection{Second-Order Election and Destructive Visibility of European Politics}

The central idea behind the theory of second-order elections is that in the electoral context of EP elections, the EU-level issues and discussions are considered less important than domestic concerns (Reif \& Schmitt, 1980). This thesis has been investigated and confirmed from multiple perspectives: from political actors' rhetoric and communication (Haßler et al., 2020), to voters' issue perceptions (Clark, 2014) and media issue focus (de Vreese et al., 2006). Importance is, therefore, frequently connected to visibility: If EU-level issues are less prominent in political and media communication as well as in voters' perceptions compared to national-level politics, then the perceived importance of the EU-level remains secondary, a fact that can potentially weaken the frequently challenged democratic legitimacy of the EU (Follesdal \& Hix, 2006).

In the last few years, however, many scholars have brought attention to the increasing politicization of European politics where numerous political conflicts are articulated on a European level (e.g., Braun \& Grande, 2021). As a result, the public visibility of European politics has enhanced significantly over the last few years (Hutter \& Grande, 2014). This heightened visibility, however, does not automatically result in a larger importance attributed to European compared to national politics. It is often argued that the current attention to European matters can be even harmful or destructive to the European integration project as it marks a shift from "permissive consensus" to "constraining dissensus" (Hooghe \& Marks, 2009), and may promote the idea that the national level is or should be more important in solving policy challenges. For these reasons, when it comes to the second-order character of European politics, it is not only the level of visibility that matters, but also the nature of this visibility, i.e., the context in which European-level political issues are embedded when they are discussed in the public sphere. The context that can result in "harmful" or "destructive" visibility for the European level can be broken into macro-, meso-, and micro-dimensions.

On the macro-level, the differences across countries matter: Highly unequal visibility of EU-level issues across individual countries can be counter-productive. This is especially true when the visibility is strongly associated with general support toward the EU. If the visibility of European-level issues is significantly higher in countries which are already supportive of the EU, then this visibility gap may deepen the general EU-attitude gap across 
these countries. Here, people in countries with a generally positive attitude toward integration will see more EUlevel content, while in more Eurosceptic nations the dominance of the domestic level can reinforce the generally negative attitudes (cf. Hutter \& Kriesi, 2019). Integration can only be enhanced by visibility which is relatively equally distributed across the member states.

On the meso-level, several studies demonstrated that the politicization of the EU-level is largely fueled by populist parties whose adversarial attitude can increase the visibility of the EU in a destructive way (e.g., Hutter \& Grande, 2014). Populism is nowadays considered a major challenge for European integration (Van Kessel, 2015). However, while populist parties' approach to politics and policy ideas often contradicts the basic values of the EU (Norris \& Inglehart, 2019), they effectively place the European level at the foreground of their communication.

On the micro-level, the immediate communication context can also produce destructive visibility for EU matters. The European political level can be addressed in varying ways. Its second-order character can be most effectively mitigated when policy topics are discussed at the EU-level or "through the EU" (Hertner, 2015, p. 471). However, the EU-level is often addressed through specific external events or topics bringing forward the role of the EU, but only on specific, transitional, often conflicting topics that could or should be solved by European institutions. Based on this differentiation, Senninger and Wagner (2015) distinguished between full and selective mobilization scenarios of party communication. Full mobilization occurs when parties discuss a wide array of policy topics on the EU-level, while selective mobilization refers to when parties selectively choose topics addressing the EU-level. While both strategies can increase the visibility of European politics, we argue that only the former can mitigate the second-order character of European politics. By contrast, selective mobilization limits the EU-level to some specific, externally driven, often temporary and instrumentalized topics, while keeping most policy issues on the national level. Another micro context-related concern is that parties (Eugster et al., 2020) and the media (Seddone et al., 2019) often frame EU-level politics in a negative way. When presented negatively, the larger visibility of EU-level politics cannot contribute to decreasing its second-order character as people will be more skeptical and dismissive of the EU (van Spanje \& de Vreese, 2014).

In our research we will focus on both (a) the general visibility, and (b) the macro-, meso- and microcontext of the visibility of the European level that can result in a "destructive" visibility for European politics. However, on social media, visibility is not only a matter of politicians' and media communication but is also influenced by the degree to which users engage with content. Therefore, we test the second-order election hypothesis and the related "destructive visibility" thesis by investigating users' engagement with party posts.

\subsection{User Engagement and the Visibility of European Politics}

On social media, which have become one of the main political information resources for many voters (Newman et al., 2020), visibility largely depends on what kind of content users engage with due to the viralitybased dissemination logic of these platforms (Klinger \& Svensson, 2015) and the engagement-centric operation of content-filtering algorithms (Bucher, 2012). Here, highly reacted-to posts are more visible on social media sites as reactions can appear on friends' News Feeds, and posts with more reactions are more likely to be selected by the algorithm to be shown to users.

Beyond these direct effects on the public agenda, user engagement can also have an indirect effect on the visibility of political content. Provoking users' reactions with their posts is one of the main strategic goals of political actors' social media communication as this is a highly effective way to reach users beyond their followers cost-effectively (Kelm, 2020). Studies show that political actors intensively monitor user engagement patterns (McGregor, 2020) and make efforts to adjust their communication to users' preferences (Ennser-Jedenastik et al., 2021). Consequently, if users are seemingly more interested in national politics, parties are pushed to focus on the national level more intensively to gain reactions, while if users are more dedicated to Europeanlevel content, political actors are motivated to communicate about European-level issues. In addition, the context of EU-level communication can be also shaped by users' preferences if they engage with certain types of EU content more than with others. For these reasons, user engagement with party posts can have considerable influence on the second-order character of EP elections: Users can shape the public visibility of party messages directly and affect parties' communication indirectly.

However, while much recent research has examined media and political actors' approaches to EU-level politics, citizens' social media engagement is a rather unexplored area, especially when it comes to their engagement with political actors' posts. A few studies have examined user online activity in general as it relates to certain European issues (e.g., Bossetta et al., 2018; de Wilde et al., 2014), but to our knowledge, voter interaction with political actors' national- and EU-level content has been investigated by only two recent studies. First, drawing upon the same dataset used here, Haßler et al. (2020) examined issue ownership and second-order elections, finding no significant difference between the median values of shares provoked by national- and EU-focused posts across 12 European countries. However, their approach was descriptive, and no confounding factors or country- or party-level differences were considered. Therefore, their conclusion could not move beyond the fact that, in the total dataset, European-level posts are shared as frequently as domestic content. Second, Fazekas et al. (2021) employed 
multivariate techniques to investigate the distinct effect of political level on user engagement. In their crosscountry research they found that, during the 2014 EP election campaign, users were less likely to respond to EP candidates' EU-focused posts on Twitter, but the differences were modest, and the effect sizes were not uniform across countries.

In this article, we aim to move beyond previous work as our focus here is the unique and contextdependent effect of European-focused content on all general engagement types on Facebook. Therefore, we follow the research agenda of Fazekas et al. by conducting multivariate cross-country research on user engagement with political actors' EU- and national-level posts. Our focus, however, is on party Facebook pages rather than candidate Twitter pages. We investigate parties who are players in both the European and national political spheres in contrast with EP candidates investigated by Fazekas et al. (2021) whose sole focus was the European level. In the European context, Facebook is the most popular social media platform (Newman et al., 2020). Therefore, this is where users' political engagement can make a true difference in the public visibility of EU-level political information. However, Bossetta et al. (2017) argue that Facebook is a less appropriate space for transnational activity than Twitter due to, inter alia, its network structure. On Facebook, users are more embedded into their extended offline network than on Twitter which is a more interest-driven platform, and hence they are more motivated to publicly engage with political content that is locally relevant. These findings suggest that EU-level posts will be even less popular in this context than in those investigated by Fazekas et al. (2021). Further, findings about citizens' lower involvement in EU-level activities (Baglioni \& Hurrelmann, 2016) suggest that on a platform that is more representative of the general population than Twitter (Bossetta et al., 2017), people will engage with European-level posts to a lesser degree. Hence, we hypothesize:

$\mathrm{H} 1$ : Users are less likely to engage with EU-level than with national-level posts on parties' Facebook pages.

If $\mathrm{H} 1$ is supported, then user engagement patterns will further increase the second-order character of EP elections. However, in line with our theoretical argument discussed above, we also assume that user engagement patterns are not uniform. It is important to uncover what context-related factors can make EU-level content more or less popular among users. This way we could test the "detrimental visibility" thesis, arguing that the EU-level is more likely to be engaged with by users when it is presented in a way that is harmful to the European integration process. Engagement with EU-level posts may be determined by whether countries are already highly supportive toward European integration or by the prominence of populist parties who challenge the basic values of the European Union. Further, engagement may also be triggered by the salience of specific topics or when messages are framed in a negative way. For these reasons we also investigate how macro- (country), meso- (party), and micro-level (message content) factors moderate the effects of EU-focused content on user engagement.

\subsection{Macro-Level: Engagement Gap Across Countries}

Even though EP election campaigns take place simultaneously in all member states, neither the national campaigns nor user engagement are cross-nationally uniform. For example, in countries more supportive towards the EU, parties might focus more strongly on the EU-level in their campaigns and users might engage more strongly with EU-level posts than in countries with rather skeptical attitudes towards the EU. This might lead to a cross-country visibility gap which can be detrimental to the integration process: It would lead to an even higher visibility of countries already supportive towards the EU, thus increasing the gap in perceived importance of the EU-level. However, research on the cross-country differences in user engagement pattern is scarce, and this is especially true when it comes to their engagement with EU-level content. The abovementioned study from Fazekas et al. (2021) found that countries differ from each other in terms of the popularity of EU-level content on candidates' Twitter pages, but this study is limited to four countries (Germany, Greece, Spain, UK). We extend this approach to the 12 countries involved in our sample. However, given the thin research base, we formulate an open research question focusing on the cross-country differences:

RQ1: How far did engagement patterns with parties' posts on EU-level content differ cross-nationally in the 2019 EP election campaign?

The 12 countries we investigate differ with respect to several structural features. Table 1 in the Supplementary File shows the high level of variation between the countries in our sample and includes-besides variables related to EU support-a number of factors that might help interpret our results. However, motivated by the destructive visibility thesis, our main focus is if there is a visibility gap of the EU-level between supportive and more Eurosceptical countries.

\subsection{Meso-Level: The Populist Threat}

Alongside such potential macro influences on user engagement with European-focused campaign posts, research also demonstrated differences across parties (Adam \& Maier, 2016). We therefore expect that certain parties are more effective in provoking user engagement with their EU-level content than others, which affects the way general social media users are exposed to European politics on these platforms. In line with $\mathrm{H} 1$ we expect that the EU-level will be less popular than the national level for each party type, but we also assume that the gap between 
the popularity of the two levels can be narrower in the case of populist parties compared to non-populist parties.

Reinemann et al. (2016) identified three distinct forms of populist appeals: empty populism, anti-elitism, and exclusionary populism. Empty populism means political actors addressing "the people" as representatives of the disempowered masses. Anti-elite and exclusionary populism blame the elites or out-groups for current problems. Populist appeals can be effectively connected to the EU-level which may make populist parties' EU-level communication particularly popular among users: The bureaucratic setup of EU-level decision-making can be easily criticized from an anti-elite perspective, while its democratic deficit can be effectively contrasted with the people-centric perspective. As the immigration crisis was also addressed by European institutions, anti-immigration rhetoric fits also well into EU-level communication. Therefore, we hypothesize:

$\mathrm{H} 2$ : The gap between the engagement levels of EUand national-focused posts is smaller for populists than non-populist parties.

\subsection{Micro-Level: Selective and Negative Mobilization}

Previous work showed that the second-order character is conditioned by content-related factors. European-level content can be presented in different ways, and it is possible that it is more popular among users in certain forms than others. Two recurring concerns are investigated here: the selective mobilization thesis, and the negative framing of European politics. Our basic assumption is the same as for the effect of populist parties: Based on $\mathrm{H} 1$, we presume that the EU-level will be less engaged with irrespective of the associated content elements (main effect), but the gap between the two levels can be more moderate for some content types than for others (interaction effect).

When it comes to the selective mobilization thesis discussed above, the role of specific issues should be considered. Although the issue focus of party EU-level political communication has been previously investigated (e.g., Senninger \& Wagner, 2015), we do not know if users are selectively engaging with topics addressed on the EU-level. During the 2019 EP election campaign, there were two policy issues salient in almost every EU member state (European Commission, 2019) that both heavily impact national politics in member states and have an important EU-level policy dimension: environmental policy/climate change and immigration policy. Both issues are at the center of political conflicts that can be observed across Europe and often relate to the EU-level, while also being contested across parties. Party campaigns are, however, at the same time focused on traditional policy issues such as economy and social/labor policy-topics that are almost always salient in political campaigns and have strong European dimensions as well (Green-Pedersen \& Walgrave, 2014). If the selective mobilization thesis is valid for user engagement, we can expect that an EU-focus on the salient issues of environmental and immigration policy will be more rewarded by users than other prominent policy issues such as economy and social/labor policy.

H3: The gap between the engagement levels of EUand national-focused posts is smaller when they are associated with environmental policy ( $\mathrm{H} 3 \mathrm{a})$ or immigration policy (H3b).

H4: The gap between the engagement levels of EUand national-focused posts is larger when they are associated with economy ( $\mathrm{H} 4 \mathrm{a}$ ) or labor/social policy (H4b).

Regarding the negative visibility thesis, when it comes to user engagement in particular, negativity has a strong potential to make content more visible. Previous research demonstrates that voters pay closer attention to negative content in political campaigns (Meffert et al., 2006). Consistent with this, studies show that specifically on Facebook, users are more likely to engage with negative than with positive or neutral posts (e.g., Bene et al., 2021). While negativity is a productive strategy to trigger engagement in general, there are arguments that this may be especially popular when articulated on the EU-level: Even though European citizens' confidence in the EU and its institutions has increased over the last years, it is still rather low. In 2019, for example, only $43 \%$ of Europeans tended to trust the EU and its institutions (European Commission, 2019). As argued above, the EU is an easy target to blame and make responsible for people's dissatisfaction and distrust in politics. Due to the impersonal, bureaucratic nature of its institutions, it cannot effectively defend itself from political attacks. Given the overall high level of dissatisfaction with and distrust towards the EU, we hypothesize:

H5: The gap between the engagement levels of EUand national-focused posts is smaller when they are framed in a negative way.

\section{Methods}

To answer our research question and test the hypotheses, we conducted a standardized content analysis of posts on official party Facebook pages during the EP election campaign of 2019. The data were collected in our collaborative research project "Campaigning for Strasbourg" (CamforS; see https://digidemo.ifkw.Imu.de/camfors). We coded 9,688 posts from 12 countries (Austria, Denmark, France, Germany, Hungary, Ireland, Italy, Poland, Romania, Spain, Sweden, and the UK) deriving from the pages of parties that reached more than $5 \%$ of the votes during the EP election. The sampling period covers the 28 days before the election including the election day $(26 / 05 / 2019$, with the exception of the 
UK where it was 23/05/2019). Based on coding capacities and sample sizes, in some countries we coded the full sample, while in others a random sample was drawn from the posts (see Table 1 in the Supplementary File for sample sizes). The Facebook posts were collected using Facepager (Jünger \& Keyling, 2019) and CrowdTangle (for Romania and Denmark; CrowdTangle, 2021). To ensure the reliability of the empirical instrument, all collaboration partners jointly developed the coding scheme. The Facebook posts from the 12 countries were coded by $1-5$ coders in the individual country teams. To test for reliability, a random sample of 48 posts from the Facebook pages of European parties was coded by all coders. The reliability of the categories used proved to be good (all Holsti above .70).

Dependent variables: User engagement is analyzed by means of three indicators: (a) the reactions to posts, defined as the sum of Facebook "likes" and "reactions" (e.g., "love," "wow"); (b) the number of "comments;" and (c) the number of "shares."

Independent variables: All categories on the content level of posts were coded as binary variables indicating whether a content characteristic was absent ("0") or present ("1") in its text, pictures, or videos. To analyze the impact of the addressed "political level" within a post, we differentiated whether a post referred to five different levels ("global," "EU," "national," "local," or "other level," where this last one is a residual category including, e.g., bilateral relations beyond the previously mentioned levels). In our models, we focus only on the EU-level with the national level as a reference category by controlling local, global, and other levels. Topics of posts were measured by categories capturing if certain policy issues were addressed in a post. Here, we focus on the topics of "immigration policy," "environmental/energy policy," "economy/finance," and "labour/social issues." "Negativity" of a post was coded when the post contained any negative statements. Parties were differentiated according to their status as being a populist party or not, based on the categorization of The PopuList (Rooduijn et al., 2019).

Control variables: To account for different post features that could influence user engagement but are beyond our focus of interest, we included a variety of control variables to our analyses: We controlled for the presence/absence of images/videos in a post, the number of words, the inclusion of hyperlinks, the day a post was published, the number of followers of a Facebook page, and the number of posts published on that page. Additionally, we controlled for the electoral support of parties included in the analyses (for descriptives see Table 2 in the Supplementary File).

\section{Findings}

\subsection{Country Differences (Macro-Level)}

To investigate cross-country differences, we calculated correlation coefficients between the focus of the posts (both on EU- and national-level) and user engagement metrics. However, we used a standardized version of these metrics rather than their raw values to control for the differences in the level of user activity across party pages.

The last two columns of Table 1 show that the degree to which posts addressed the EU- and national-level differs cross-nationally. However, this seems to be less strongly related to attitudes towards the EU. In Denmark, Ireland, Poland, Italy, and the UK, parties focused particularly strongly on the national level in their Facebook posts. People in Denmark, Poland, and Ireland are generally supportive toward the EU, but Italy and the UK are among the more Eurosceptic countries (Table 1 in the Supplementary File). Situational factors may be important here: All these countries held national elections in close temporal connection with the EP election, with the UK campaign conducted in the shadow of Brexit. Austria, Spain, and Hungary-which apart from Hungary also held national elections-displayed a moderate focus on the national level. In the other countries which did not hold national elections, we see an equal share of EU- and national-level posts (Romania) or the campaign focused on the EU-level (France, Germany, Sweden). Based on these observations, it seems that the secondorder character of the EP elections in parties' communication is at least partly conditioned by the closeness of national elections.

Turning to user engagement patterns, our findings show that users engage with posts addressing the EU-level to a different degree in different countries. In France, Ireland, and Romania, user engagement does not significantly differ depending on the levels addressed. In Italy, Spain, Austria (for reactions and comments), and Hungary (for reactions and shares), users are significantly more engaged with the national than with the EU-level; again, countries (with the exception of Hungary) that held other elections in close proximity to the EP election. Although differences in the correlation coefficients are not significant, they are rather substantial in the case of Germany (only for shares) and Sweden (only for reactions) where national-level posts seem to be much more popular, and in Denmark (for reactions and shares), Poland (for comments and shares), and the UK (only for reactions) where the EU-level attracted more user engagement. Thus, we see an overall mixed pattern: On the one hand, countries with more similar user engagement patterns are rather heterogeneous both geographically, politically, and in their EU-related factors. On the other hand, situational factors in terms of close domestic elections do not explain these patterns either. Moreover, how strongly the parties focus on the EU- vs. national-level in their Facebook posts does not seem to uniformly affect user engagement patterns across countries. A more remarkable congruence between party communication and user engagement patterns can be seen in Austria, Hungary, Italy, Spain, and Romania, but strongly divergent patterns are 
Table 1. Pearson's correlation between a posts' political level and their user engagement metrics in standardized form by countries.

\begin{tabular}{|c|c|c|c|c|c|c|c|c|}
\hline & \multicolumn{2}{|c|}{ Reactions } & \multicolumn{2}{|c|}{ Comments } & \multicolumn{2}{|c|}{ Shares } & \multicolumn{2}{|c|}{$\%$ of Posts } \\
\hline & EU & national & EU & national & EU & national & EU & national \\
\hline Austria & $-.14 * * *$ & $.09 *$ & $-.12 * *$ & $.11 * *$ & -.06 & .06 & $45 \%$ & $60 \%$ \\
\hline Denmark & .01 & $-.14^{*}$ & -.05 & .05 & -.03 & $-.16^{*}$ & $19 \%$ & $93 \%$ \\
\hline France & -.01 & -.00 & .00 & -.00 & .03 & -.00 & $58 \%$ & $46 \%$ \\
\hline Germany & -.05 & .00 & -.03 & .01 & $-.11 *$ & .07 & $69 \%$ & $27 \%$ \\
\hline Hungary & $-.11 * *$ & $.10^{*}$ & -.04 & .04 & $-.13 * * *$ & $.11 * *$ & $39 \%$ & $61 \%$ \\
\hline Ireland & -.09 & -.07 & -.08 & -.01 & -.01 & .01 & $25 \%$ & $88 \%$ \\
\hline Italy & $-.06 * *$ & .04 & $-.08 * * *$ & $.09 * * *$ & $-.05^{*}$ & $.06 *$ & $32 \%$ & $69 \%$ \\
\hline Poland & .17 & $.17^{*}$ & .12 & -.12 & $.35 * * *$ & .12 & $9 \%$ & $77 \%$ \\
\hline Romania & .00 & -.03 & -.02 & .01 & -.01 & .05 & $57 \%$ & $59 \%$ \\
\hline Spain & $-.16 * * *$ & $.30 * * *$ & $-.10 * *$ & $.19 * * *$ & $-.12 * * *$ & $.19 * * *$ & $17 \%$ & $40 \%$ \\
\hline Sweden & -.09 & .08 & -.01 & -.02 & .02 & .04 & $72 \%$ & $16 \%$ \\
\hline UK & .09 & $-.14^{*}$ & .00 & -.09 & .05 & -.07 & $19 \%$ & $66 \%$ \\
\hline
\end{tabular}

Notes: Standardized user engagement metrics are the deviations from the mean number of reactions, comments and shares of the specific parties expressed in standard deviation. ${ }^{*} p<.05 ; * p<.01 ; * * p<.001$. Significant differences between correlation coefficients (based on their confidence intervals) are highlighted in bold. The variables EU-level and national-level are not mutually exclusive, therefore one post can belong to both or none of these categories.

evident in Denmark, Poland, the UK, Sweden, Germany, and Ireland. Overall, it seems that while there are substantial cross-country differences, these do not result in a visibility gap between supportive and Eurosceptic countries as the variances are not related to EU support (Table 1 in the Supplementary File).

\subsection{Direct and Indirect Effects on User Engagement With EU-Level Content (Meso- and Micro-Level)}

To test the effects of party- and content-level factors, we conducted multilevel negative binomial regression models with random intercept on the level of parties and country fixed effects. As local, global, and other levels are added as control variables, the reference category of the independent variable of "EU-level" is nationallevel; thus, EU and national levels are directly contrasted (Table 2; see the Supplementary File for the formal model expression).

As for the direct effect, it seems that people are generally less willing to react to and comment on posts focusing on the EU-level. These negative effects remain significant even when interaction terms are added. The only exception is sharing, where no significant relationship was detected when the interaction effects are entered. So, while European-focused posts are significantly less reacted-to and commented-on in line with the secondorder hypothesis, their sharing potential is no worse than that of national-level posts when the interaction effects are controlled for. Therefore, $\mathrm{H} 1$ is supported in the case of reactions and comments but rejected for sharing: The reaction- and comment-fueled visibility of Europeanlevel content may be mitigated by user preferences, but the non-significant effect of sharing indicates that, in the viral chains of sharing, European-focused content is as much present as domestic political content.

However, it is important to see what Europeanfocused content is most engaged with. It seems that populist parties-whose anti-elite rhetoric is frequently directed to the EU-level-gain less reactions, comments, and shares when focusing on the EU-level than mainstream parties (Figure 1). Interestingly, an EU-level focus has a stronger disengaging effect on the followers of populist parties than on those of mainstream parties, rejecting our H2. Populist parties whose European-level communication is frequently considered as destructive cannot reach their followers effectively with these messages, therefore the visibility of European content is more fueled by mainstream political actors.

Turning to the content-level moderators, the effects of EU-level content on user engagement seem to be rather uniform across different topics. The engagement gap between national and EU-level is practically the same for environment, economy, labor, and social policy-focused posts in each dimension. The only exception to this finding is immigration-focused posts in the case of reactions and comments (marginally significant; Figure 1). However, the direction of the interaction effect is the opposite of what we expected: Focusing on the EU-level in immigration-related posts decreases the number of reactions and comments more heavily than in the case of non-immigration posts. It seems therefore that the social media popularity of the immigration topic could be seriously undermined when it is discussed at the EU-level. In summary, we cannot find any major topic where EU-focus is more popular than suggested by the 
Table 2. Random-intercept negative binomial regression estimates for reactions, comments, and shares on parties' posts.

\begin{tabular}{|c|c|c|c|c|c|c|}
\hline & $\begin{array}{l}\text { Reaction } \\
\text { (model 1) }\end{array}$ & $\begin{array}{l}\text { Reaction } \\
\text { (model 2) }\end{array}$ & $\begin{array}{l}\text { Comment } \\
\text { (model 1) }\end{array}$ & $\begin{array}{l}\text { Comment } \\
\text { (model 2) }\end{array}$ & $\begin{array}{c}\text { Share } \\
(\text { model } 1)\end{array}$ & $\begin{array}{c}\text { Share } \\
\text { (model 2) }\end{array}$ \\
\hline European level & $-.19(.02) * * *$ & $-.11(.04)^{* *}$ & $-.35(.03)^{* * *}$ & $-.24(.05)^{* * *}$ & $-.16(.03)^{* * *}$ & $.01(.05)$ \\
\hline immigration & $.20(.05)^{* * *}$ & $.29(.06)^{* * *}$ & $.09(.07)$ & $.19(.09)^{*}$ & $.30(.06)^{* * *}$ & $.35(.08)^{* * *}$ \\
\hline environment & $-.26(.04)^{* * *}$ & $-.20(.06)^{* * *}$ & $-.36(.06)^{* * *}$ & $-.35(.08)^{* * *}$ & $-.28(.06)^{* * *}$ & $-.38(.07)^{* * *}$ \\
\hline economy & $-.10(.04)^{* *}$ & $-.13(.05)^{* *}$ & $-.23(.05)^{* * *}$ & $-.24(.06)^{* * *}$ & $-.08(.04)^{\#}$ & $-.02(.06)$ \\
\hline labor \& social policy & $-.06(.03)^{*}$ & $-.04(.04)$ & $-.23(.04)^{* * *}$ & $-.23(.05)^{* * *}$ & $.12(.04)^{* *}$ & $.13(.05)^{* *}$ \\
\hline negativity & $.24(.03)^{* * *}$ & $.25(.03)^{* * *}$ & $.49(.04)^{* * *}$ & $.52(.04)^{* * *}$ & $.58(.03)^{* * *}$ & $.67(.04)^{* * *}$ \\
\hline populist party & $.87(.15)^{* * *}$ & $.91(.15)^{* * *}$ & $.62(.20)^{* *}$ & $.68(.20)^{* * *}$ & $.97(.16)^{* * *}$ & $1.05(.16)^{* * *}$ \\
\hline EU + immigration & & $-.21(.09)^{*}$ & & $-.25(.13)^{\#}$ & & $-.14(.12)$ \\
\hline EU + environment & & $-.10(.08)$ & & $-.03(.11)$ & & $.19(.10)^{\#}$ \\
\hline EU + economy & & $.10(.07)$ & & $.04(.10)$ & & $-.12(.09)$ \\
\hline EU + labor \& social policy & & $-.08(.06)$ & & $.00(.09)$ & & $-.04(.08)$ \\
\hline EU + negativity & & $-.02(.05)$ & & $-.09(.07)$ & & $-.29(.07)^{* * *}$ \\
\hline EU + populist party & & $-.11(.05)^{*}$ & & $-.17(.07)^{*}$ & & $-.20(.06)^{* *}$ \\
\hline local level & $-.19(.03)^{* * *}$ & $-.18(.03)^{* * *}$ & $-.17(.04)^{* * *}$ & $-.18(.04)^{* * *}$ & $-.43(.04)^{* * *}$ & $-.44(.04)^{* * *}$ \\
\hline global level & $-.18(.08)^{*}$ & $-.18(.08)^{*}$ & $-.22(.11)^{*}$ & $-.23(.11)^{*}$ & $-.16(.10)$ & $-.14(.10)$ \\
\hline other level & $-.05(.12)$ & $-.04(.12)$ & $-.20(.17)$ & $-.20(.17)$ & $.18(.16)$ & $.18(.15)$ \\
\hline image & $.35(.07)^{* * *}$ & $.35(.07)^{* * *}$ & $.14(.09)$ & $.13(.09)$ & $.34(09)^{* * *}$ & $.34(09)^{* * *}$ \\
\hline video & $.01(.07)$ & $.01(.07)$ & $.50(.10)^{* * *}$ & $.49(.10)^{* * *}$ & $.59(.09)^{* * *}$ & $.59(.09)^{* * *}$ \\
\hline wordcount & $.00(.00)^{* *}$ & $.00(.00)^{* *}$ & $-.00(.00)$ & $-.00(.00)$ & $.00(.00)^{* * *}$ & $.00(.00)^{* * *}$ \\
\hline link & $-.27(.03)^{* * *}$ & $-.27(.03)^{* * *}$ & $-.05(.04)$ & $-.06(.04)$ & $.09(.04)^{*}$ & $.08(.04)^{\#}$ \\
\hline day & $.00(.00)^{*}$ & $.00(.00)^{*}$ & $.00(.00)^{* *}$ & $.00(.00)^{* *}$ & $-.00(.00)$ & $-.00(.00)$ \\
\hline num_followers & $.00(.00)^{* *}$ & $.00(.00)^{* *}$ & $.00(.00)^{* * *}$ & $.00(.00)^{* * *}$ & $.00(.00)^{* * *}$ & $.00(.00)^{* * *}$ \\
\hline num_posts & $-.00(.00)^{*}$ & $-.00(.00)^{*}$ & $-.00(.00)^{*}$ & $-.00(.00)^{*}$ & $-.00(.00)^{* * *}$ & $-.00(.00)^{* * *}$ \\
\hline electoral support & $.01(.01)^{*}$ & $.01(.01)^{*}$ & $.03(.01)^{* * *}$ & $.03(.01)^{* * *}$ & $.02(.01)^{*}$ & $.02(.01)^{*}$ \\
\hline constant & $5.03(.25)^{* * *}$ & $4.99(.25)^{* * *}$ & $2.57(.34)^{* * *}$ & $2.54(.34)^{* * *}$ & $2.44(.27)^{* * *}$ & $2.36(.27)^{* * *}$ \\
\hline $\begin{array}{l}\text { variance of random } \\
\text { intercept }\end{array}$ & $.21(.45)$ & $.21(.46)$ & $.37(.61)$ & $.37(.61)$ & $.22(.47)$ & $.23(.48)$ \\
\hline Log-likelihood & -49933.8 & -49926.1 & -35448.6 & -35441.1 & -39950 & -39926 \\
\hline disp. parameter & 1.31 & 1.31 & 0.73 & 0.73 & 0.83 & 0.84 \\
\hline AIC & 99931.6 & 99928.2 & 70961.2 & 70958.2 & 79964 & 79928 \\
\hline N Level 1/Level 2 & $7012 / 67$ & $7012 / 67$ & $7000 / 67$ & $7000 / 67$ & $7017 / 67$ & $7017 / 67$ \\
\hline
\end{tabular}

Notes: Standard errors are in parentheses. ${ }^{\#} p<.10 ;{ }^{*} p<.05 ;{ }^{* *} p<.01 ;{ }^{* *} p<.001$. Party fixed effects are included in the models, but not presented in the table. Significant differences between correlation coefficients (based on their confidence intervals) are highlighted in bold.

direct effect, and immigration is definitely not the issue where EU-level focus can gain larger acceptance by the audience, but environment is not an attractive supranational topic either. On the other hand, as no topic was detrimental to EU-focus, our findings suggest that users are not selectively mobilized in EU-related matters ( $\mathrm{H} 3$ and $\mathrm{H} 4$ rejected). The engagement with EU-level content is not topic-specific, and most importantly, not driven by conflicting, often transitional hot topics which would result in destructive visibility of European politics.
Our last hypothesis-exploring the micro-levelconcerned negativity. After shifting the negative content of the posts to the EU-level, the results turned out to be contrary to our initial assumptions and revealed that there are no significant differences in user engagement for negative posts in terms of reactions and comments (Figure 1). In fact, the moderating effect of negativity on user interactivity is only significant for shares, albeit in the opposite direction to what we expected. Negative posts are shared much less frequently when addressing 

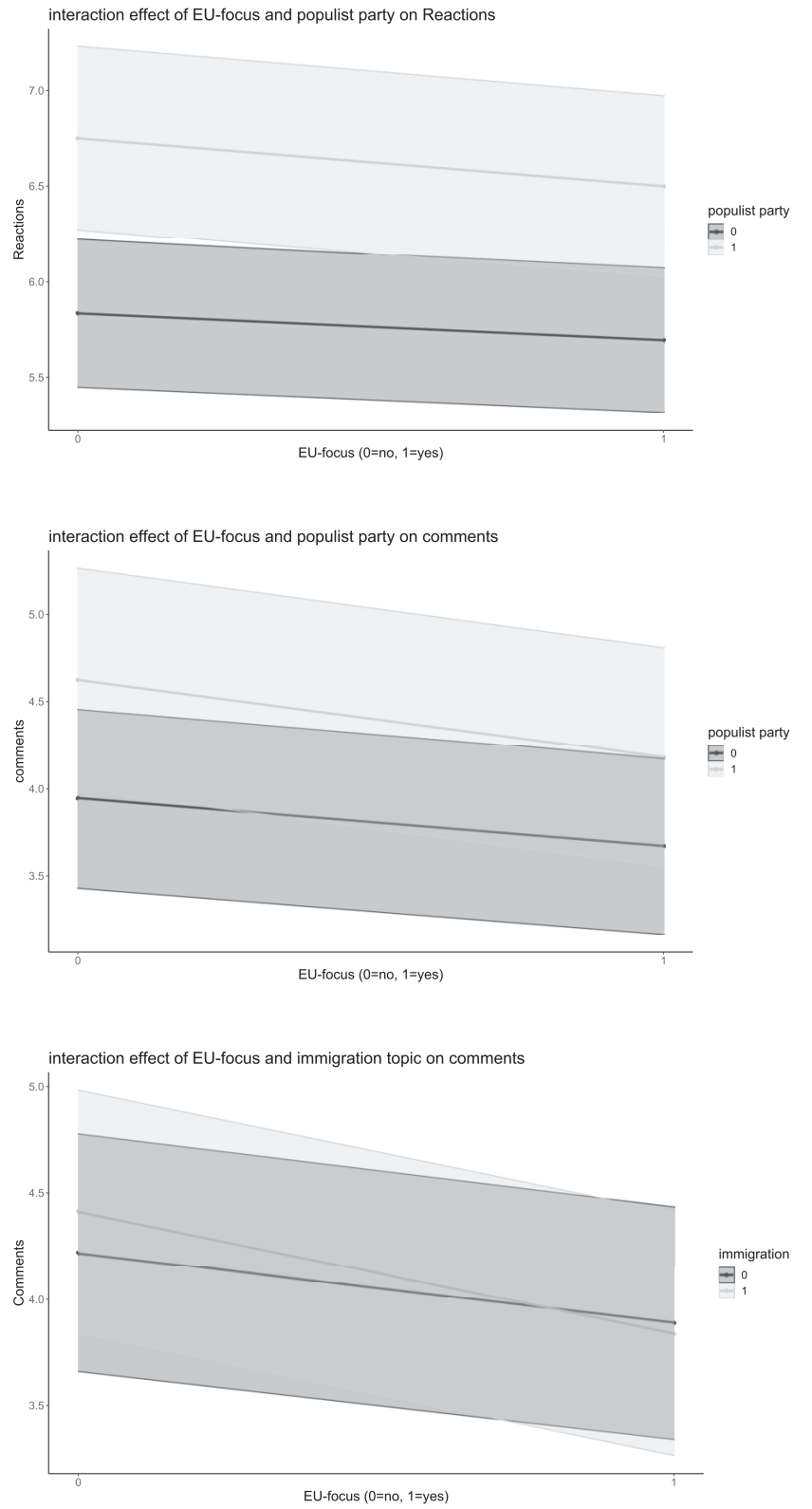

Figure 1. Significant interaction effects.

the EU-level than when addressing the national level. It seems that in the case of negative posts, addressing the EU-level has a stronger deterrent effect on sharing than in the case of non-negative posts (H5 rejected). It can be concluded that negativity does not appear to be a driver of increased social media user engagement at the EU-level, therefore negative framing of European politics is not motivated by users' preferences.

\section{Conclusion}

Our research focused on one dimension of citizen engagement with European politics, namely engagement via Facebook as a response to the campaigns of political parties across 12 member states during the 2019 EP election. While across the nations we find a mixed
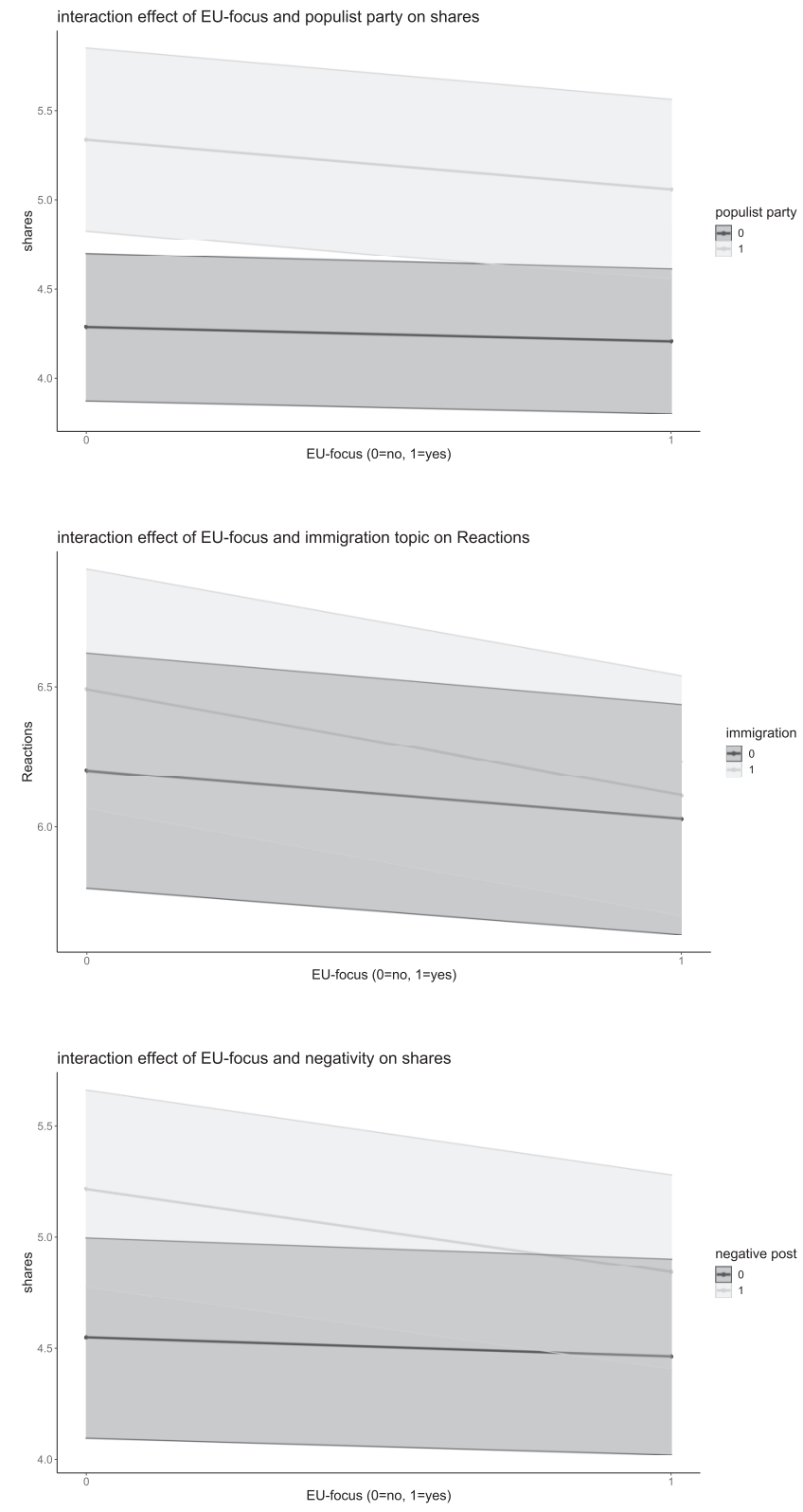

agenda, incorporating national and European politics, largely those Facebook users who engage with parties' posts seem more likely to react to or comment on posts that focus on national issues. Reinforcing the findings of Fazekas et al. (2021), we find those who engaged with political party posts were significantly less likely to make any reaction or comment to posts that focused on policy at the EU-level. Hence these engagement patterns may drive the character of EP elections towards a greater ethnocentric focus as parties strive to post content which is attractive to their followers and the wider community (Ennser-Jedenastik et al., 2021). On this basis, EU-level politics may become increasingly invisible during future contests, reinforcing its second-order character. If EU politics is less visible, it may never be seen as salient, and citizens will be unlikely to develop any understand- 
ing of the relevance of the EP and the EU beyond times of crisis when media does offer it some attention. This scenario could only exacerbate disconnections between European citizens and the institutions of the EU, thus deepening the EU's supposed democratic deficit.

However, our data does not offer a wholly negative picture. First, there are remarkable differences across countries, and there is a rather heterogeneous set of countries where EU-focused posts are no less popular than national posts. Second, if party posts do not focus on any of the topics investigated here, and do not contain negative sentiments, they are as likely to be shared as similar posts focusing on national-level politics. As sharing is important for a post being visible to a broader range of the users of a social media platform, we may suggest that more posts of this nature can elevate the relevance of the EU. Third, concerns regarding the more divisive, selective, and negative presence of EU-level politics can also be rejected. There is no engagement gap between supportive and more Eurosceptic countries, populist parties are not more successful with their EU-focused content, and people do not selectively engage with European content based on its topics or negative valence. In fact, posts on immigration or with negative valence or content which are produced by the populist parties are often less likely to be engaged with by users when focusing on EU-level. Therefore, while there is an engagement gap, and EU politics gains less engagement, at least the engagement is not received for posts that would exacerbate extant levels of mistrust and Euroscepticism.

We therefore speculate that, actually, European politics can spread within social media platforms in a less divisive and negative way than we expected. Research has found that posts which express negative sentiments by focusing on controversial issues such as immigration, and by adopting a populist tone, receive greater engagement among users (Bene et al., 2021). However, we find that higher engagement is mostly awarded to these posts when the focus is on domestic politics and not the EU-level. While this can be divisive within a nation, it may not have the deleterious effect on trust in the EU that we might expect. This speculative argument is however based purely on engagement with the posts of political parties on one platform. It may be that other platforms see differing patterns of engagement which run counter to our findings. Also, this research covered only national parties which are crucial actors of European politics, but individual politicians also matter. Future studies should uncover if the patterns identified here are different for the pages of political leaders or European politicians.

Nonetheless, our research can be seen as an important step toward understanding the role user engagement may play in the second-order character of EU politics. Our findings suggest that pro-European actors need to make serious efforts to bring the EU closer to the people, but the silver lining is content of a divisive nature appears unattractive for social media users.

\section{Acknowledgments}

This publication is part of the work of the junior research group "DigiDeMo" which is funded by the Bavarian State Ministry of Science and the Arts and coordinated by the Bavarian Research Institute for Digital Transformation (bidt) and also supported by the Incubator program of the Center for Social Sciences, Eötvös Loránd Research Network (project number: 03013645) and Bolyai János Research Fellowship awarded by the Hungarian Academy of Sciences (BO/334_20).

\section{Conflict of Interests}

The authors declare no conflict of interests.

\section{Supplementary Material}

Supplementary material for this article is available online in the format provided by the author (unedited).

\section{References}

Adam, S., \& Maier, M. (2016). Campaigning on or downplaying EU integration? Explaining the salience parties attach to EU matters in European Parliamentary election campaigns. In W. van der Brug \& C. H. de Vreese (Eds.), (Un-) intended consequences of European Parliamentary elections (pp. 148-170). Oxford University Press.

Baglioni, S., \& Hurrelmann, A. (2016). The Eurozone crisis and citizen engagement in EU affairs. West European Politics, 39(1), 104-124.

Bene, M., Ceron, A., Fenoll, V., Haßler, J., Kruschinski, S., Larsson, A. O., Magin, M., Schlosser, K., Wurst, A.-K., Lilleker, D., \& Maurer, P. (2021). Engaging users through information or critique? "Likes" and "shares" for parties on Facebook during the 2019 European election campaign [Paper presentation]. Weizenbaum Conference 2021: Democracy in FluxOrder, Dynamics and Voices in Digital Public Spheres.

Blumler, J. G. (2016). The fourth age of political communication. Politiques de communication, 6(1), 19-30.

Boomgaarden, H. G., de Vreese, C. H., Schuck, A. R. T., Azrout, R., Elenbaas, M., Spanje, J. H. P. V., \& Vliegenthart, R. (2013). Across time and space: Explaining variation in news coverage of the European Union. European Journal of Political Research, 52(5), 608-629.

Bossetta, M., Dutceac Segesten, A., \& Trenz, H.-J. (2017). Engaging with European politics through Twitter and Facebook: Participation beyond the national? In M. Barisione \& A. Michailidou (Eds.), Social media and European politics: Rethinking power and legitimacy in the digital era (pp. 53-76). Palgrave Macmillan UK.

Bossetta, M., Segesten, A. D., \& Trenz, H.-J. (2018). Political participation on Facebook during Brexit: Does user engagement on media pages stimulate engage- 
ment with campaigns? Journal of Language and Politics, 17(2), 173-194.

Braun, D., \& Grande, E. (2021). Politicizing Europe in elections to the European Parliament (1994-2019): The crucial role of mainstream parties. JCMS: Journal of Common Market Studies, 59(5), 1124-1141.

Bucher, T. (2012). Want to be on the top? Algorithmic power and the threat of invisibility on Facebook. New Media \& Society, 14(7), 1164-1180.

Clark, N. (2014). Explaining low turnout in European elections: The role of issue salience and institutional perceptions in elections to the European Parliament. Journal of European Integration, 36(4), 339-356.

CrowdTangle. (2021). CrowdTangle / Content discovery and social monitoring made easy. https://www. crowdtangle.com

de Vreese, C. H., Banducci, S. A., Semetko, H. A., \& Boomgaarden, H. G. (2006). The news coverage of the 2004 European Parliamentary election campaign in 25 countries. European Union Politics, 7(4), 477-504.

de Wilde, P., Michailidou, A., \& Trenz, H.-J. (2014). Converging on Euroscepticism: Online polity contestation during European Parliament elections. European Journal of Political Research, 53(4), 766-783.

Ennser-Jedenastik, L., Gahn, C., Bodlos, A., \& Haselmayer, M. (2021). Does social media enhance party responsiveness? How user engagement shapes parties' issue attention on Facebook. Party Politics. Advance online publication. https://doi.org/ 10.1177/1354068820985334

Eugster, B., Jalali, C., Maier, M., Bathelt, S., LeideckerSandmann, M., Adam, S., Negrine, R., \& Demertzis, N. (2020). When do European election campaigns become about Europe? West European Politics, 44(7), 1425-1454.

European Commission. (2019). Standard Eurobarometer 91-Spring 2019 [Data set]. Directorate-General for Communication. https://data.europa.eu/euodp/en/ data/dataset/S2253_91_5_STD91_ENG

Fazekas, Z., Popa, S. A., Schmitt, H., Barberá, P., \& Theocharis, Y. (2021). Elite-public interaction on Twitter: EU issue expansion in the campaign. European Journal of Political Research, 60(2), 376-396.

Follesdal, A., \& Hix, S. (2006). Why there is a democratic deficit in the EU: A response to Majone and Moravcsik. JCMS: Journal of Common Market Studies, 44(3), 533-562.

Green-Pedersen, C., \& Walgrave, S. (Eds.). (2014). Agenda setting, policies, and political systems: A comparative approach. The University of Chicago.

Haßler, J., Magin, M., Russmann, U., Baranowski, P., Bene, M., Schlosser, K., Wurst, A.-K., Fenoll, V., Kruschinski, S., \& Maurer, P. (2020). Reaching out to the Europeans. Political parties' Facebook strategies of issue ownership and the second-order character of European election campaigns. In C. Holtz-Bacha (Ed.), Europawahlkampf 2019: Zur Rolle der Medien [European election campaigning 2019: On the role of the media] (pp. 87-113). Springer.

Hertner, I. (2015). Is it always up to the leadership? European policy-making in the Labour Party, Parti Socialiste (PS) and Sozialdemokratische Partei Deutschlands (SPD). Party Politics, 21(3), 470-480.

Hooghe, L., \& Marks, G. (2009). A postfunctionalist theory of European integration: From permissive consensus to constraining dissensus. British Journal of Political Science, 39(1), 1-23.

Hutter, S., \& Grande, E. (2014). Politicizing Europe in the national electoral arena: A comparative analysis of five West European countries, 1970-2010. JCMS: Journal of Common Market Studies, 52(5), 1002-1018.

Hutter, S., \& Kriesi, H. (2019). Politicizing Europe in times of crisis. Journal of European Public Policy, 26(7), 996-1017.

Jünger, J., \& Keyling, T. (2019). strohne/Facepager: Facepager was made for fetching public available data from YouTube, Twitter and other websites on the basis of APIs and webscraping. Github. https:// github.com/strohne/Facepager

Kelm, O. (2020). Why do politicians use Facebook and Twitter the way they do? The influence of perceived audience expectations. SCM Studies in Communication and Media, 9(1), 8-34.

Klinger, U., \& Svensson, J. (2015). The emergence of network media logic in political communication: A theoretical approach. New Media \& Society, 17(8), 1241-1257.

McGregor, S. C. (2020). "Taking the temperature of the room": How political campaigns use social media to understand and represent public opinion. Public Opinion Quarterly, 84(S1), 236-256.

Meffert, M. F., Chung, S., Joiner, A. J., Waks, L., \& Garst, J. (2006). The effects of negativity and motivated information processing during a political campaign. Journal of Communication, 56(1), 27-51.

Newman, N., Fletcher, R., Andi, S., \& Nielsen, R. K. (2020). Reuters Institute digital news report 2020. University of Oxford.

Norris, P., \& Inglehart, R. (2019). Cultural backlash: Trump, Brexit, and authoritarian populism. Cambridge University Press.

Reif, K., \& Schmitt, H. (1980). Nine second-order national elections-A conceptual framework for the analysis of European election results. European Journal of Political Research, 8(1), 3-44.

Reinemann, C., Aalberg, T., Esser, F., Strömbäck, J., \& de Vreese, C. H. (2016). Populist political communication: Toward a model of its causes, forms, and effects. In T. Aalberg, F. Esser, C. Reinemann, J. Stromback, \& C. de Vreese (Eds.), Populist political communication in Europe (pp. 22-36). Routledge.

Rooduijn, M., van Kessel, S., Froio, C., Pirro, A., de Lange, S., Halikiopoulou, D., Lewis, P., Mudde, C., \& Taggart, P. (2019). The PopuList. https://popu-list.org

Seddone, A., Bobba, G., \& Roncarolo, F. (2019). European 
versus domestic politics: Media negativity during the 2019 European Elections campaign in Italy. Italian Political Science, 14(2), 73-92.

Senninger, R., \& Wagner, M. (2015). Political parties and the EU in national election campaigns: Who talks about Europe, and how? JCMS: Journal of Common Market Studies, 53(6), 1336-1351.

Trimithiotis, D. (2020). The persistence of ethnocentric framing in online news coverage of European politics.
Digital Journalism, 8(3), 404-421.

Van Kessel, S. (2015). Populist parties in Europe: Agents of discontent? Springer.

van Spanje, J., \& de Vreese, C. (2014). Europhile media and Eurosceptic voting: Effects of news media coverage on Eurosceptic voting in the 2009 European Parliamentary elections. Political Communication, 31(2), 325-354.

\section{About the Authors}
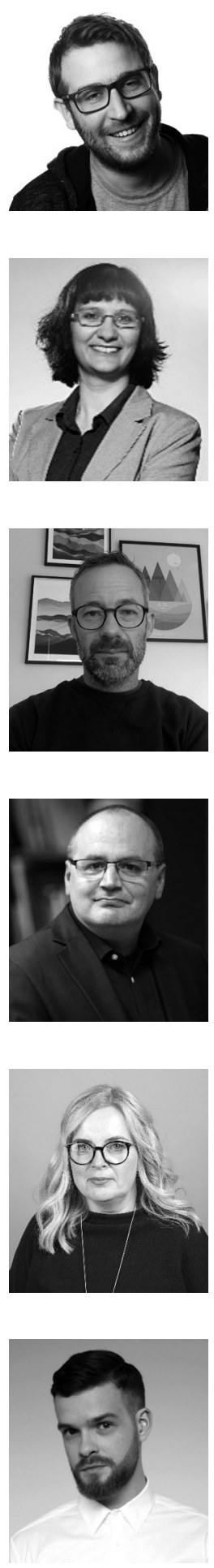

Márton Bene is a senior research fellow at the Centre for Social Sciences, an Hungarian Academy of Sciences Centre of Excellence, and lecturer at Eötvös Loránd University. His research interests are in political communication, social media and politics, and political behavior.

Melanie Magin is an associate professor in media sociology at the Norwegian University of Science and Technology (NTNU) in Trondheim and has a PhD in communication studies from JGU Mainz (Germany). She works at the intersection of political communication, online communication (particularly social media and search engines), and comparative research. Her research focuses on the societal role and impact of traditional and new media as well as the chances and risks associated with them. She is chair of the Political Communication Section of the European Communication Research and Education Association.

Daniel Jackson is professor of media and communication at Bournemouth University. His research broadly explores the intersections of media, power, and social change, including news coverage of politics, political communication, the mediation of sport, and the dynamics of civic culture in online environments. He is co-editor of the election analysis reports, published within ten days of major electoral events. Daniel is former convenor of the Political Studies Association's Media and Politics Group and convenor of the Journalism Research Group at Bournemouth University.

Darren Lilleker is professor of political communication and director of the Centre for Comparative Politics and Media Research at Bournemouth University, UK, and editor of the Palgrave series in Political Communication and Campaigning.

Delia Balaban is a communication science professor at the Department for Communication, Public Relations, and Advertising, Faculty for Political, Administrative, and Communication Sciences, within the Babeș-Bolyai University, Cluj-Napoca, Romania. Her research focuses on advertising, especially embedded advertising and political communication on social media.

Paweł Baranowski is an assistant professor at the Media Studies Department of the Institute of Journalism and Social Communication at the University of Wrocław. He is an experienced academic teacher, co-editor of scientific journals and a participant of international research projects. His research interests revolve around political communication, journalism studies, and new media, with particular focus on electoral campaigns in social media. 


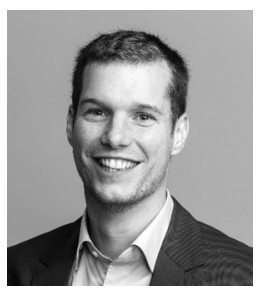

Jörg Haßler is head of the Junior Research Group "Digital Democratic Mobilization in Hybrid Media Systems (DigiDeMo)" at the Department of Media and Communication at LMU Munich. From 2011 to 2019 he was research associate (from 2016 on as post-doc) at the Universities of Jena and Mainz in the research group "Political Communication in the Online-World." His research interests include (online) campaigning, social media, political communication, and empirical methods.

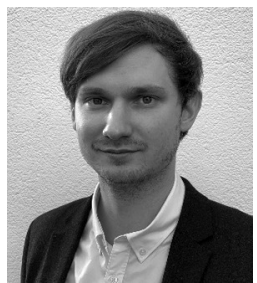

Simon Kruschinski is a research associate and PhD student in the Political Communication Division at the Department of Communication of the Johannes Gutenberg-University Mainz, Germany. His research focuses on technology-intensive election campaigns and how data and analytics are used to persuade or mobilize voters on- and offline. Furthermore, he is interested in the theoretical, empirical, and institutional opportunities and challenges of computational communication science for political communication research.

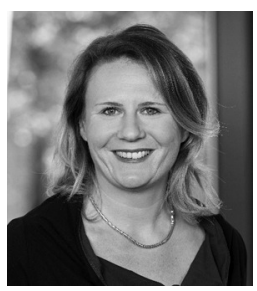

Uta Russmann is a professor of media and communication studies with a focus on democracy research at the Department of Media, Society and Communication at the University of Innsbruck, Austria. Her research focuses on political communication, media and election campaigns, digital communication, (visual) social media, public relations, and strategic communication. 